\title{
Combining data envelopment analysis and competitive dynamic theory for exploring global smartphone manu- facturers' performance
}

\author{
Wei-Lun Tsai ${ }^{1 *}$, Ping-Teng Chang ${ }^{2}$ \\ ${ }^{1,2}$ Department of Industrial Engineering and Enterprise Information, Tunghai University, Taichung, Taiwan
}

\author{
Keywords \\ Competitive dynamic \\ DAE \\ BCG matrix \\ Smartphone
}

Received: 28 February 2018

Accepted: 21 March 2018

Published: 18 April 2018

\begin{abstract}
According to the latest research report released by the Global System for Mobile Communications Association (GSMA), it is estimated that the number of mobile users will increase to 5.7 billion by 2020. Representing Mobile Communications and smartphones has changed the world. In the recent decade, the smartphone market has been booming. Taiwan manufacturers have entered the market early and have good performance. However, in recent years, smartphone annual market sales have gradually decreased, leading to intensified market competition. This study explores the well-known brand manufacturers in the smartphone market. In a dynamic environment, how the interaction between competitors affects the competition results and finally affects the business performance. This study uses the competitive dynamic theory as an analytical tool to explore the competitor's competitive process and apply Data Envelopment Analysis (DEA) to calculate the performance of firms after a competition. Finally, the results are combined with the BCG matrix to summarize the direction and suggestions for Taiwan manufacturers to improve further. The results of this study are 1 . All of the competitor's efficiency performances are maintained in good condition. The key factor that impacts whether a company can continue to grow or not is Malmquist Index. 2. Dominant Design Paradigm can be regarded as a demarcation point. Before that, patent application, trademark, and intellectual property rights as the main competitive advantage. After that, supply chain integration, marketing channel, brand value as the main competitive advantage.
\end{abstract}

(c) 2018 The Author(s). Published by TAF Publishing.

\section{INTRODUCTION}

According to the latest research report published by the GSMA, smartphone users are expected to soar to 5.7 billion in 2020, equivalent to three-fourths of the world population. Representing Mobile Communications and smartphones has changed the world. According to the statistics released by International Data Corporation (IDC), the global shipment of smartphones in 2016 was 1.49 billion units with an annual growth rate of $4.78 \%$. In recent years, the global shipment of feature phone was only 396 million in 2016. The change in shipments shows that consumers are constantly changing their demand for mobile devices. Since the 1990s, the Product Life Cycle (PLC) has been gradually shortened and the industrial environment has been changing rapidly.
It's become more difficult for those who want to prevent competitors from entering the market by a long-term advantage. Competitive advantage will fade over time. Instead, companies must continually look for short-term advantages. The only way to make the enterprise survive is thinking in Competitive dynamic way. In the recent decade, the smartphone market has been booming. Taiwan manufacturers have entered the market early and have good performance. However, in recent years, smartphone annual market sales have gradually decreased, leading to intensified market competition. This study explores the wellknown brand manufacturers in the smartphone market. In a dynamic environment, how the interaction between competitors affects the competition results and finally affects the business performance. This study uses the competitive

\footnotetext{
${ }^{*}$ corresponding author: Wei-Lun Tsai

†email: s1013328@gmail.com
} 
dynamic theory as an analytical tool to explore the competitor's competitive process and apply DEA to calculate the performance of firms after competition. Finally, the results are combined with the BCG matrix to summarize the direction and suggestions for Taiwan manufacturers to improve further.

\section{LITERATURE REVIEW Competitive Dynamic}

The concept of competitive dynamic strategy is how to properly grasp the opportunities and understand that when the advantages faded over time, giving up the original and establishing another new one. The process is based on competition and interaction. It is important for a company to understand the competitive actions and responses among its competitors (Endang, 2017; Smith \& Grimm, 1991). Competitive advantage between enterprises will not be the same. Instead, it is temporary and short. In such a dynamic competition environment, the competition among enterprises must take the possible responses from competitors into consideration. M. J. Chen (1996) proposed two aspects to describe the relationship between competitors:

(1) Market Commonality: The level of Multimarket Contact between the two companies determines whether the companies are direct or indirect competitors and consider the importance of each competitor.

(2) Resource Similarity: Refers to the similarity in resources or ability between competitors.

Considering these two aspects at the same time, there are three factors that will drive the competition among manufacturers: Awareness and Motivation mainly determine market relations, while Capability mainly depends on strategy or resources.

\section{Market Commonality}

Industry usually consists of multiple markets, and each market may present different strategies (Harrigan, 1985; Sundar \& Al Harthi, 2015). Montgomery (1985) think that from a competitive point of view, different markets will have different sets of competitors, and the market influence of each competitor will vary from market to market. Each market plays a different role for the overall market performance of each company (M. J. Chen \& MacMillan, 1992; Srisangkaew, 2017). In short, each market is unique. When two competitors compete in the market where the others main source of revenue is competing, they will regard each other as the most direct competitor.

\section{Resource Similarity}

The viewpoint of resource similarity comes from the Resource-Based View (RBV). When businesses got the different resources and assets, they also use the different way to manage it, making each one distinctness (Barney, 1991). Businesses find a competitive advantage in the industry through a unique mix of resources (Conner, 1994). M. J. Chen (1996) constructed Competitor Mapping from the two aspects of market commonality and resource similarity, proposed the method to find out the relationship between competitors. When the competitors do not have too much overlapping in the market, the business will not have a motivation to respond to competitive actions. Awareness, Motivation, Capability are the key factors that whether competitors take competitive action or not.

\section{Awareness}

Awareness is the most important factor among the three factors. When an enterprise fails to detect changes in the external environment or neglects it, it will put the enterprise in danger. M. J. Chen and MacMillan (1992) use the relative size of competitors, the amount of competitors' attacks for detection. The bigger is the size of competitor, the easier to detect any action from the competitor.

\section{Motivation}

When hit back can acquire benefits or if choose not to hit back will be a major crisis, it will form a strong counterattack motivation. For example, in 2009, due to the continuous growth of sales in the smartphone market, Nokia's sales volume in the feature phone market has obviously decreased. This has obviously affected the company's revenue and has formed a strong motivation to hit back.

\section{Capability}

M. J. Chen (1996) pointed out that the ability of an enterprise involves the control of resources because enterprises with more resources can have more options to respond. Apple filed a patent lawsuit with HTC in the United States in March 2010. Apple began to apply for patents in the smartphone market in the early stage, accumulating aggressive patent to infringe HTC on patent rights. The patent is the important resource of Apple, which makes Apple have the ability to fight back.

Analyze and identify the relationship between competitors through market commonality and resource similarity. This relationship will affect the driving factors, and it (Awareness, Motivation, and Capability) will further affect the possibility of competitive action and response, and get the result after competition finally. The competition process is a 
feedback loop, when manufacturers complete every competition means competition behavior may change the present situation, which is also the market commonality and re- source similarity relationship between manufacturers may change, will be for the next competition campaign to build a new competitive relationship.

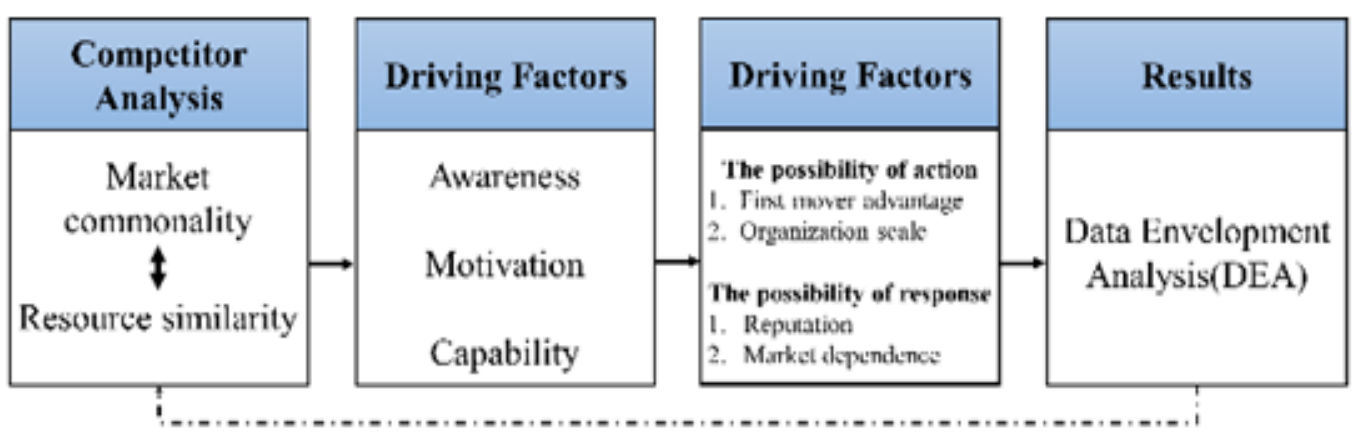

Fecdback loop

FIGURE 1. Competitive dynamic process

\section{Data Envelopment Analysis}

DEA is derived from three scholars of Charnes, Cooper, and Rhodes (1978) based on the efficiency model proposed by the Farell scholar in 1957. The initial development of the DEA model is to provide the efficiency assessment of nonprofit organizations, and then it is widely used in profit organizations and public sector organizations. This method can be used not only to measure the relative efficiency between competitors who belong to the same industry, but also to measure the relative efficiency between branches within a company, such as chain fast food stores, (Cook \& Seiford, 2009; Thanassoulis, 2000), but can also be used to measure the relative efficiency among companies in different regions across geographies (e.g., country, state, city). Since DEA is compared with each other through Decision Making Unit, (DMUs) to find the units that are considered as more productive, and then get the units with relatively lower production efficiency. DEA is considered to be able to assist the enterprises Performance assessment tools that identify benchmarking companies and learn to imitate (Avkiran, 2006). DEA is an important advantage of other traditional econometric methods. It does not need to make assumptions about the production function in advance (Cooper, Seiford, \& Tone, 2006; Lee, Lee, \& Kang, 2005). On the other hand, DEA does not need subjective opinions to set parameters. It belongs to a non-parametric evaluation method, making it more sensitive and objective to measurement results (Al-Sharkas, Hassan, \& Lawrence, 2008). The DEA has been widely used in the past 40 years (about 11975 related documents) (Emrouznejad \& Yang, 2018). Y. S. Chen and Chen (2009) used DEA to investigate the relative efficiency of Taiwan Semiconductor Manu facturing Company (TSMC) and other Taiwan semiconductor manufacturing companies from 1999 to 2003. Research shows:

(1) TSMC is the most efficient in the wafer fabrication industry in Taiwan.

(2) According to the results of the Malmquist Index, the semiconductor industry should import new technologies to enhance the effect of technological change.

Cook and Seiford (2009) uses two-stage DEA to explore the $R$ \& D costs the number of patents and the performance evaluation of the manufacturer's business performance in the semiconductor industry. The research time is from 2004 to 2008. Research shows: Through the Boston Consulting Group ( BCG ) matrix combined with the average market efficiency and production efficiency, the company is divided into four parts, namely, dogs, problem children, cash cows, stars, to help operators more comprehensively consider and conduct strategic analysis.

Liao and Lin (2011) use DEA to explore the performance of telecommunications in Korea and Japan. The research time is from 2002 to 2006 . The results of the study show that:

(1) The research found that the performance of large-scale companies is not necessarily better, because of the relative large-scale input costs and easy to be subject to strict regulatory supervision. If a small company can make good use of resources, also can stay in a good performance.

(2) Enterprises will invest high R\&D costs and the purchase of related equipment, such expenditure activities will affect the company's operating performance, because the investment does not immediately reflect in operating income. The researchers suggested that the follow-up researchers may reduce the operating performance of the current com- 
pany when investing heavily in $R \& D$ costs. However, it is necessary to lengthen the observation period to see if there is any improvement in the operating performance in the next few years. Finally, Malmquist Index can be regarded as an important indicator. Based on the past researches, this study will have the following characteristics:

(1) This study is based on the evaluation of multinational smartphone brand manufacturers, rather than confined in one country.

(2) Liao and Lin (2011) mentioned that when companies invest high investment, the operating performance of the current company may be reduced. However, it is necessary to lengthen the observation time. This study researches time range from 2007 to 2016, belongs to a complete research period.

This study uses the competitive dynamic theory as an analytical tool to explore the competitor's competitive process and apply DEA to calculate the performance of firms after competition. Finally, the results are combined with the BCG matrix to summarize the direction and suggestions for Taiwan manufacturers to improve further.

\section{PROPOSED METHOD}

This study will screen the appropriate smartphone manufacturers from the market as the evaluation object, and select input and output variables according to the literature review. The source of the analysis data is from the annual report published by the manufacturer as the main source of the data. Select the appropriate DEA model for analysis, and combine the results with the BCG matrix to summarize the key points. Eventually, get the conclusions and suggestions of this study. The time range of this study is set from 2007 to 2016. It has passed the introduction, growth and maturity period of smartphone product life cycle, making the analysis results of this research more complete.

\section{DISCUSSION AND ANALYSIS}

Select Decision Making Unit

In this study, Apple, Samsung, HTC, LG, ASUS, SONY, Lenovo, Huawei eight smartphone manufacturers are the evaluation object. Most importantly, the eight companies all with sales of electronic products include smartphone as the main source of revenue, meet the conditions of the homogeneity of the organization.

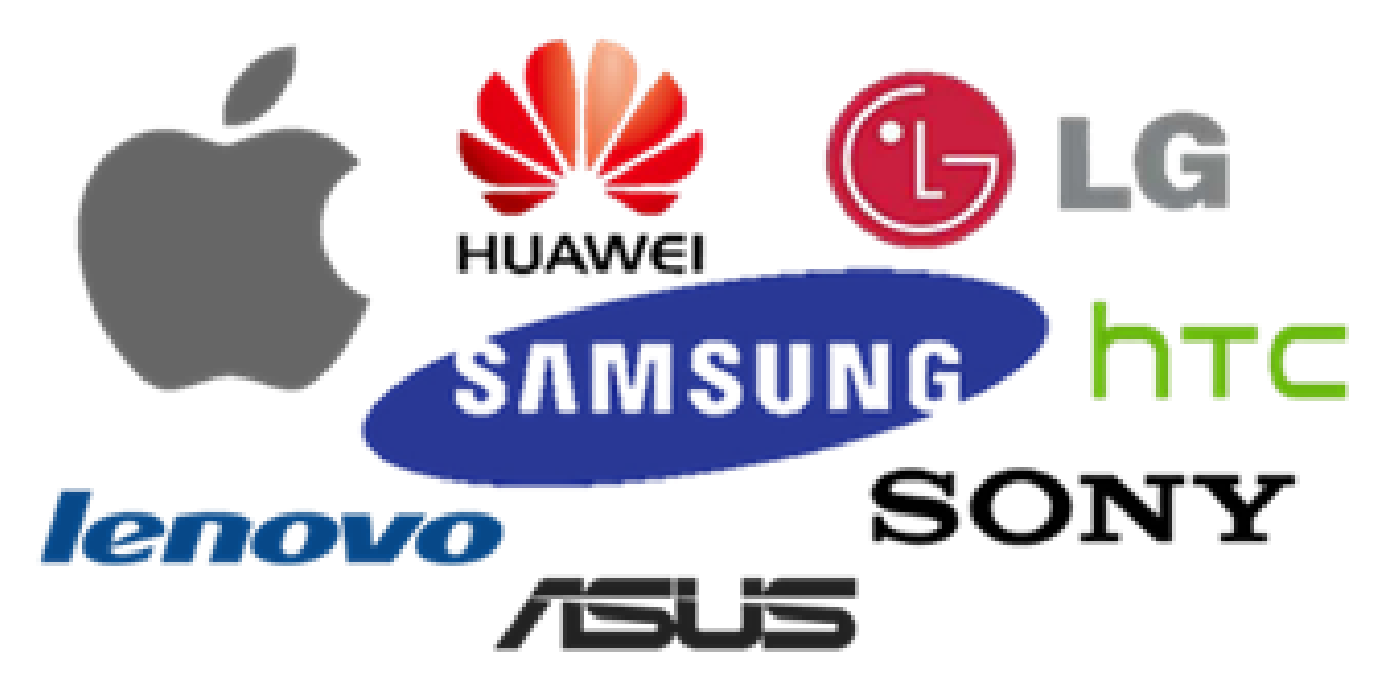

FIGURE 2. Selected smartphone manufacturers 


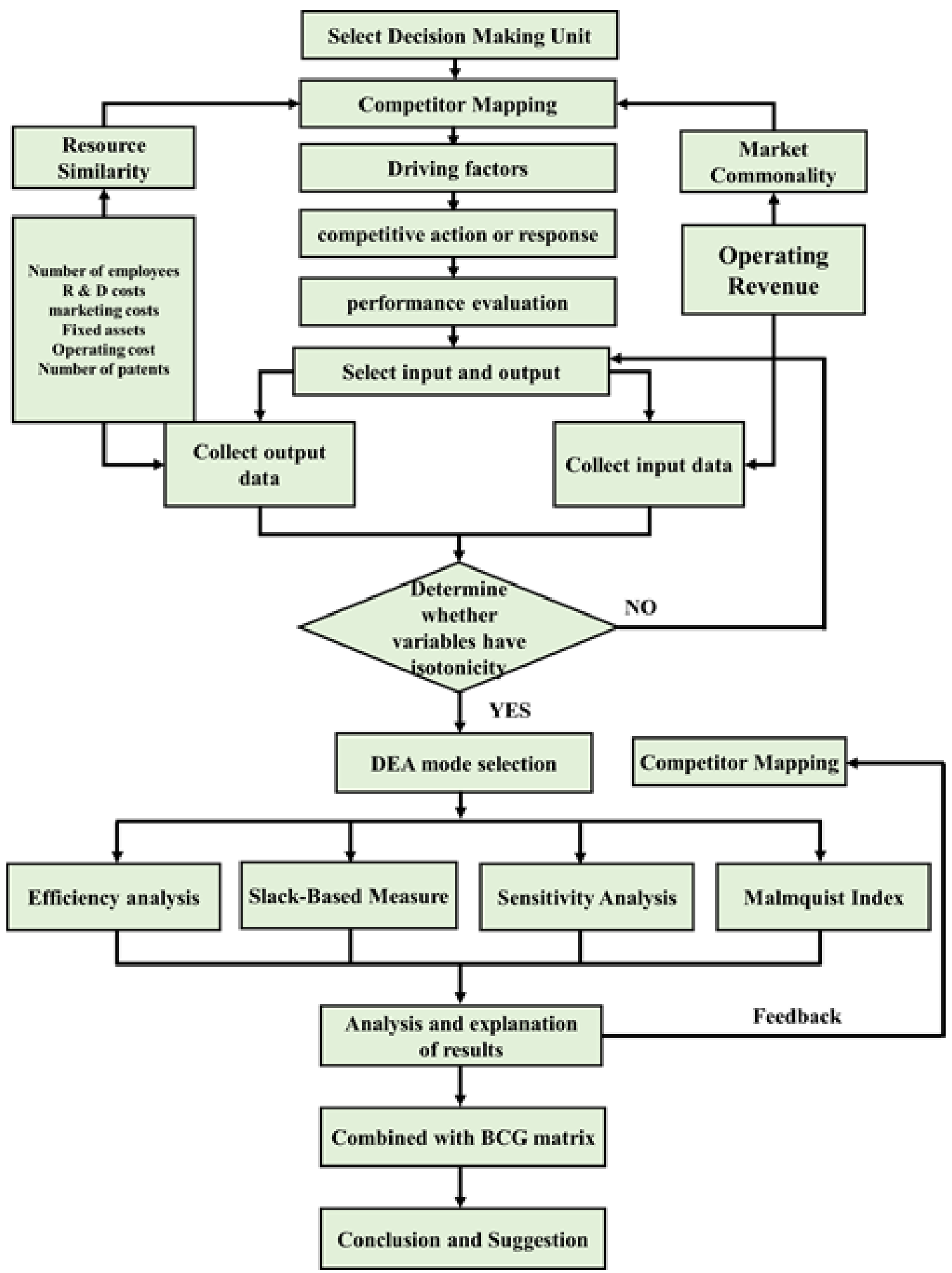

FIGURE 3. Research Process of smartphone performance evaluation

\section{Competitor Mapping}

In this study, market commonality is calculated based on the degree of overlap of revenue sources of annual regional (America, Europe, Asia) enterprises. The resource similarity is calculated based on the number of employees, R\&D expenses, marketing costs, fixed assets, Operating cost and number of patents which invested annually by the enterprise as a measure of resource similarity.

Due to the competitor's image of ten years from 2007 to 2016, the following will present the competitors' images of 
the enterprises in 2008, 2010, 2013 and 2016. From the changes in the image of competitors, we can tell that the relationship between enterprises has begun to change, as shown below:

(1) Product introduction period (2008)

In 2007, the mobile phone market was mainly dominated by feature phones. At that time, the major vendors selling feature phones were Nokia, Samsung, LG and Sony. Smartphone market was not yet shaped and restricted to the tiny market and high in selling price. Therefore, the feature phone brands have no motivation to compete with the then smart phone brand (Apple, HTC).

From the Apple's competitor mapping, the major competitors on the market are Samsung, Sony and LG, all of which are the major feature phone brands on the market. HTC also regards Samsung, Sony and LG as the main competitors. For feature phone brands, they view each other as main competitors and also give smartphone brands an opportunity to penetrate the market. This study found that the first-mover of the smartphone market is not a feature phone brand.

(2) High-growth period (2010)

By 2010, smartphones had successfully opened the market, and the relationship between competitors in the market began to change. As smart phones began to penetrate the mobile phone market, early followers (Samsung, LG and Sony) found that new business opportunities and markets were gradually forming, and they also joined the market to snatch market share.

Early followers will choose this stage to enter the market because the smartphone market is tiny, belong to the niche market. At that time, the market of feature phones was huge, so competitors did not dare to venture into new markets. On the contrary, they will observe the situation for a while at first, once they notice the market is gradually expanding, they will quickly enter the market. With the previous experience and resources accumulated in the feature phone market, the speed of deployment will be able to quickly catch up with the first-movers and narrow the gap. As the first-movers enter the market early and have few competitors, they can quickly grab the market share. From competitor mapping, the first-movers are gradually penetrating the market, accumulating resources and revenues, and gradually threatening the feature phone brand owners. Since the market at this stage is still in the devel- opment stage, the supply chain is not yet mature and stable. The smartphones sold in the market are mainly based on high-end mobile phones. In addition, the brand image of first-movers and early followers is most likely to remain in the minds of consumers.

(3) Maturing period (2013)

At this stage, a large number of late-entrants (Huawei, Lenovo, and ASUS) started to emerge. As the supply chain gradually maturing, the prices of key components are gradually dropping. Low-end and mid-end smartphones are starting to emerge. This stage will attract a large number of late-entrants into the market because the late-entrants will wait for the emergence of Dominant Design, eliminating the development costs brought by early market uncertainty, focusing on improving the cost performance of product specifications. Because the high-end smartphone market has been occupied by first-movers and early followers, attracting consumers of different groups and grabbing market share through low price strategy. The late-entrants have less experience and resource accumulation in the market than the first-movers and early followers. However, due to the mature and stable supply chain, the selling price can be reduced. Products are mainly sold in developing countries to avoid direct conflict with high-end brand manufacturers. Late-entrants can snatch market share by entering developing countries and have the ability to compete with high-end brands when they have accumulated enough experience and resources. From the competitor mapping, it is found that both the market commonality and the resource similarity are not post a threat to the first-movers and early followers. It is easy for consumers to associate the lateentrants brands with low-end and low quality because they mainly sell low price smartphones.

(4) Brand competition period (2016)

As the market continues to saturate and dominant design emerge, the differences between products shrink and consumers choose to buy based on brand image and brand loyalty. With the advantages of first-movers, Apple continues to increase brand value through its high quality and high price image. Apple continues to accumulate resources from the market, continuously acquires the latest technologies and patents by Merger and acquisition enterprise, integrates resources into its own products, and enhances its competitiveness. 
Apple

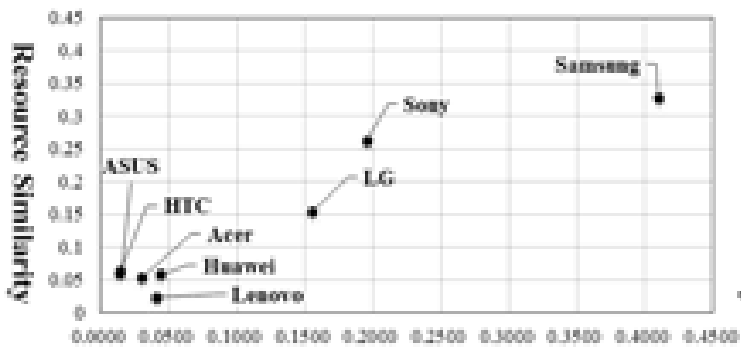

Market Commonality
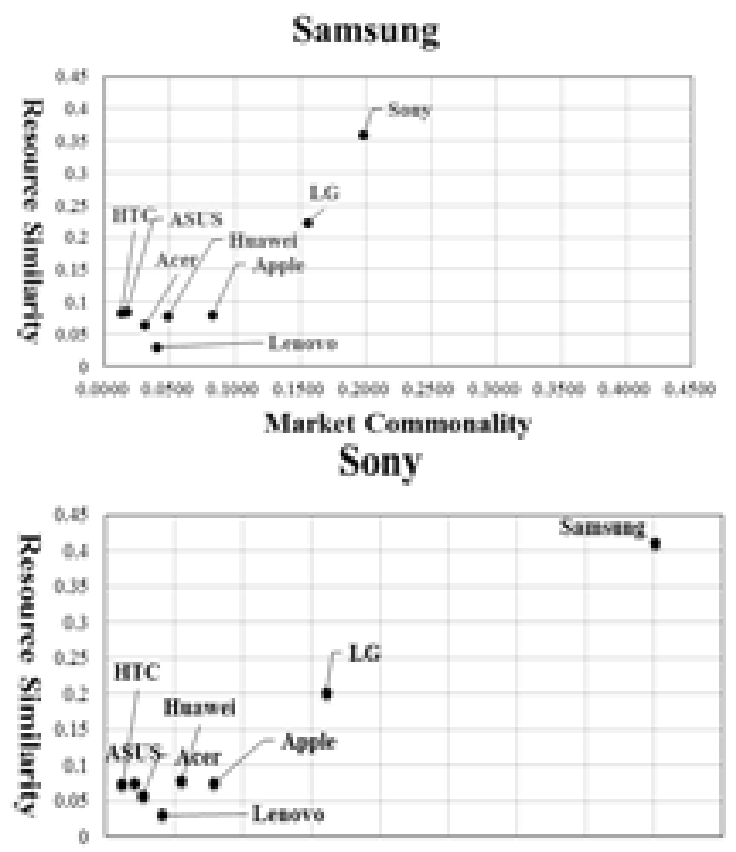

0.0000 0.4500 0.1000 0.1500 0.3000 6.2500 6.3000 0.3500 0.4500 0.4500

Market Commonality

ASUS

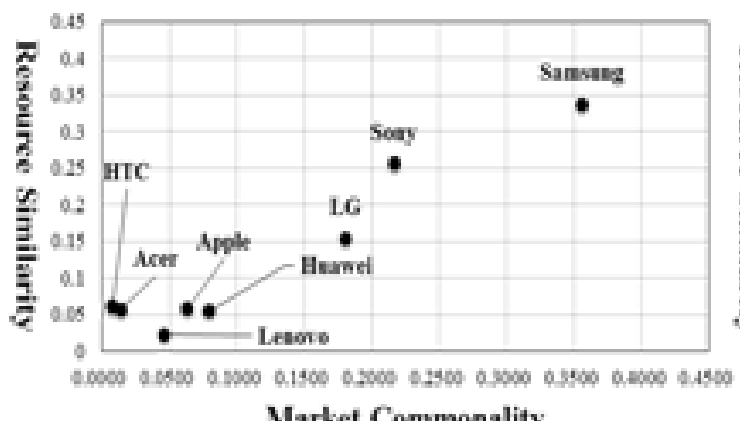

Market Commonality
HTC

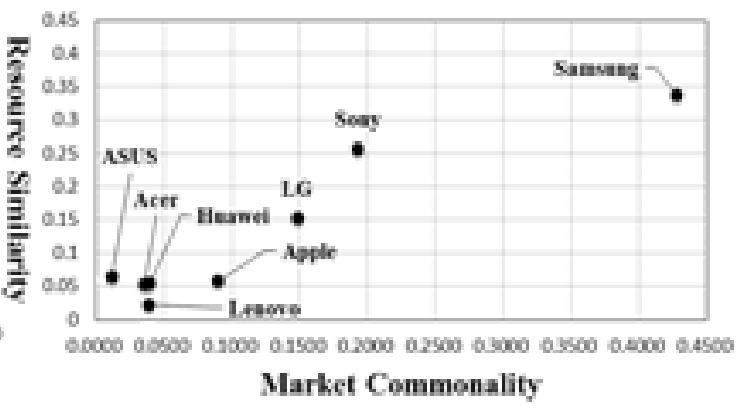

LG

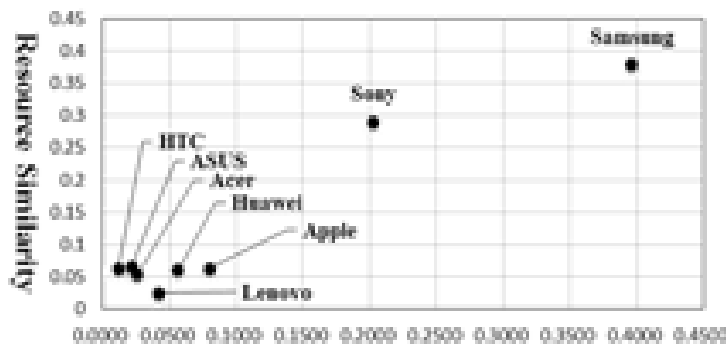

Market Commonality

Huawei

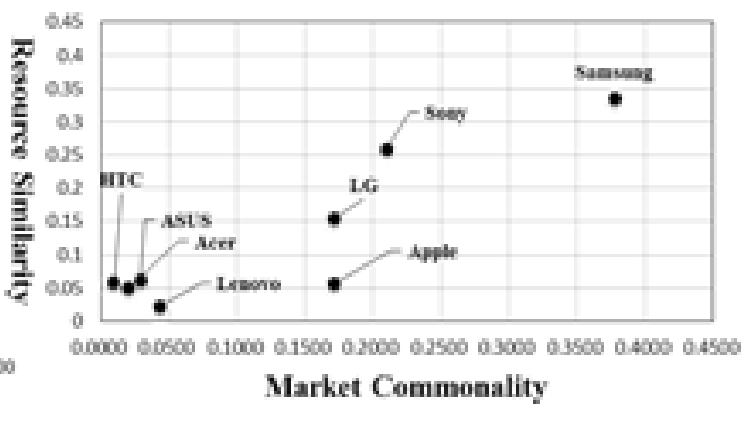

Lenovo

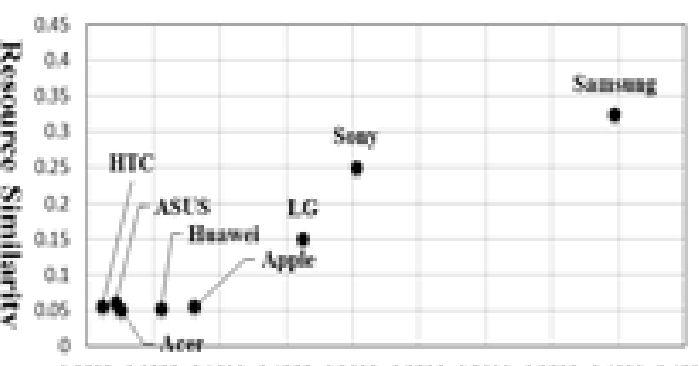

00000 0.0500 0.5000 0.1500 0.2000 0.3500 0.3000 0.3500 0.4500 0.4500

Market Commonality

FIGURE 4. Competitor Mapping in 2008 
Apple

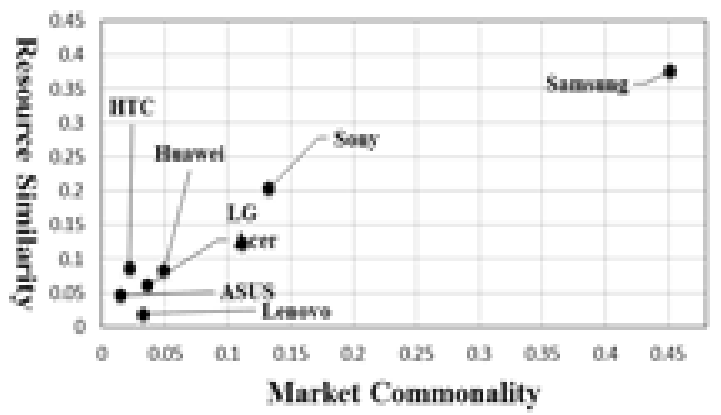

Samsung

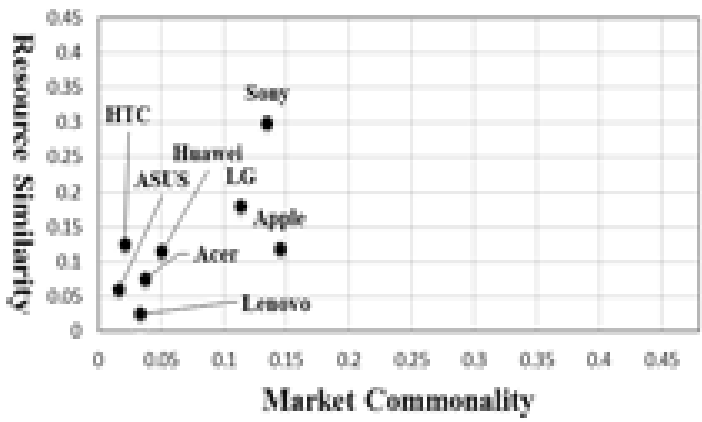

Sony

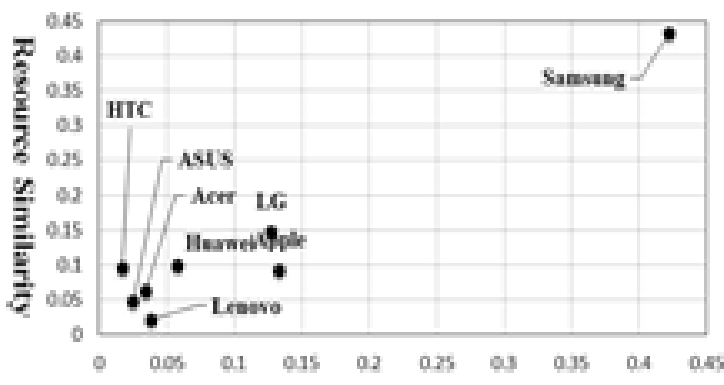

Market Commonality

ASUS

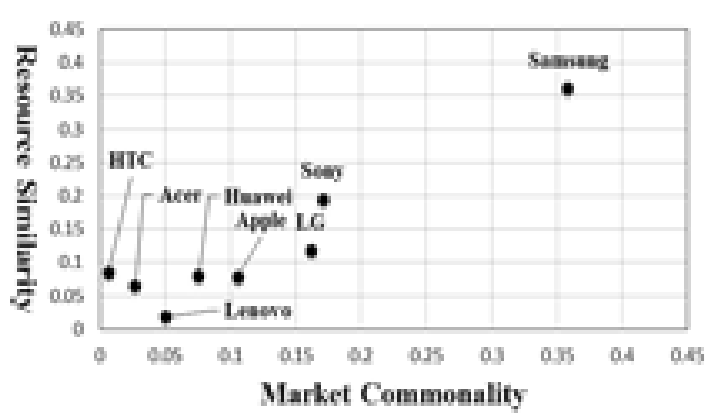

HTC

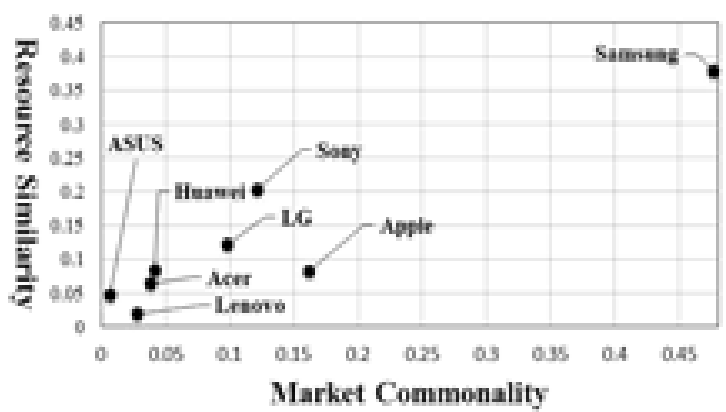

LG
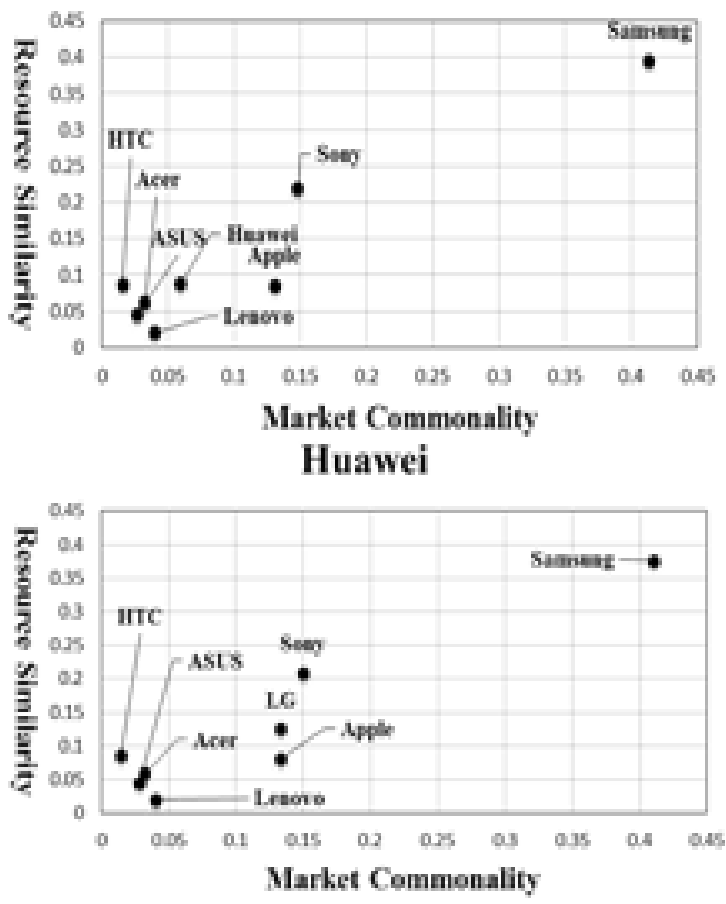

Lenovo

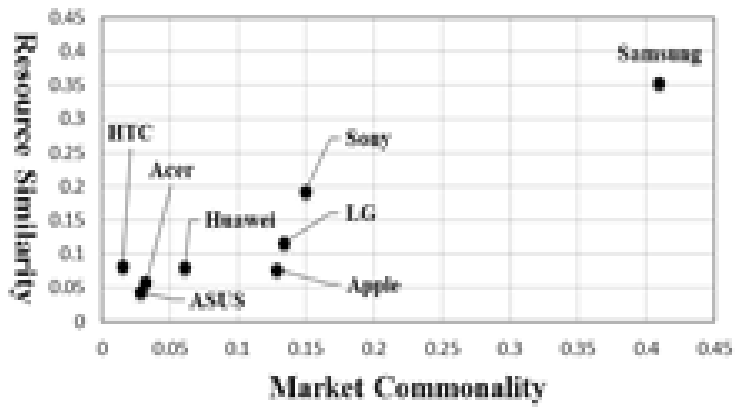

FIGURE 5. Competitor mapping in 2010 
Apple
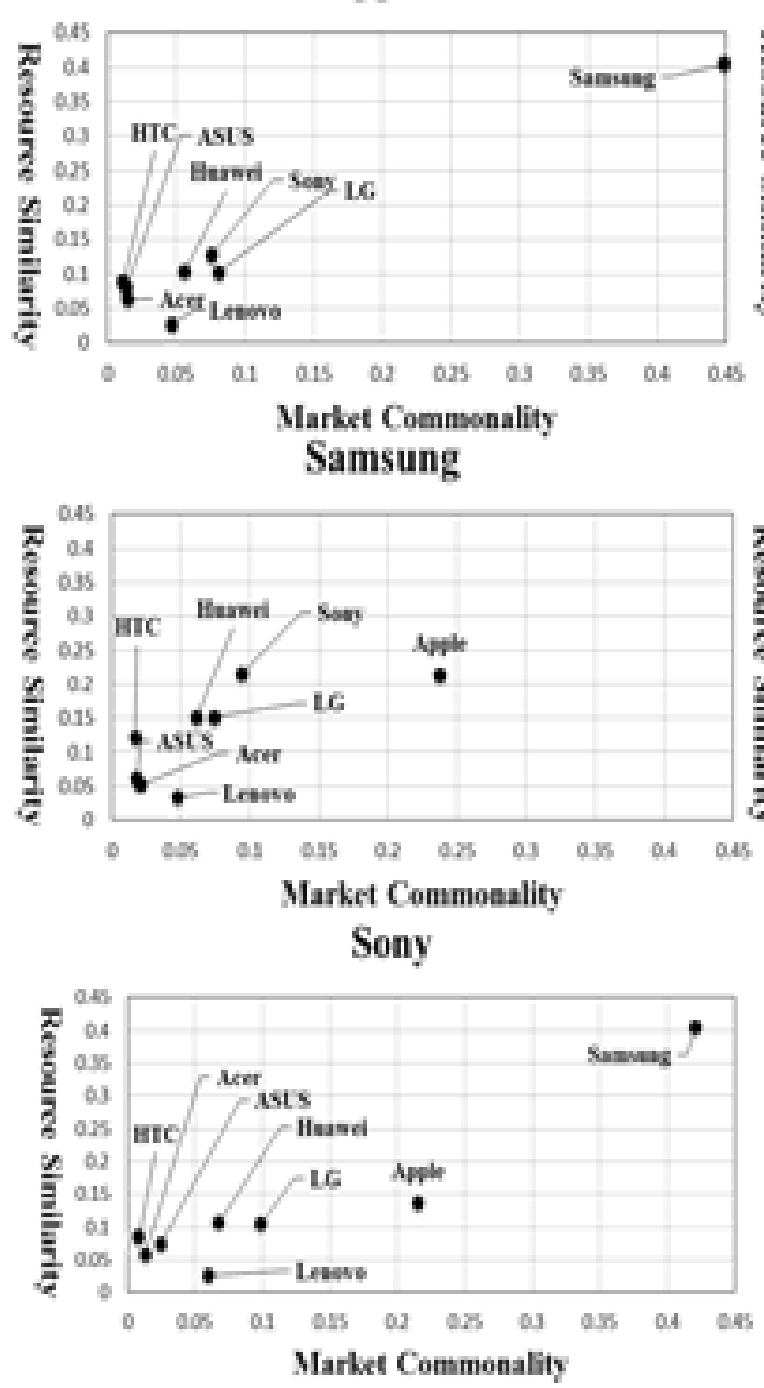

ASUS

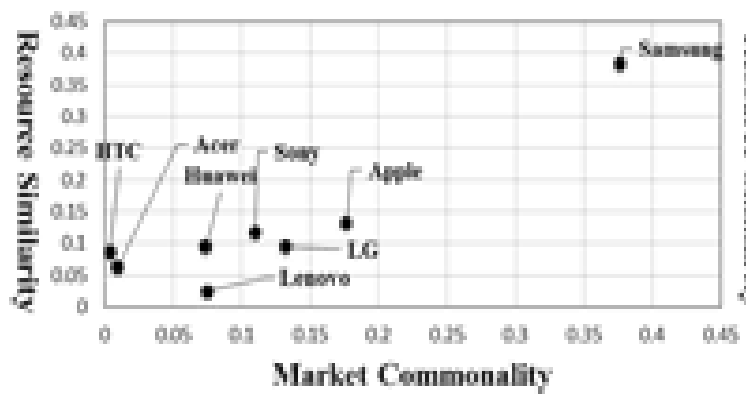

FIGURE 6. Competitor mapping in 2013

With the rich of experience in the mobile phone market, Samsung is well known for high vertical integration in the supply chain, enabling products to be rapidly developed, manufactured, and delivered to the market. Samsung has invested heavily in R\&D and marketing cost, which not only

\section{HTC}

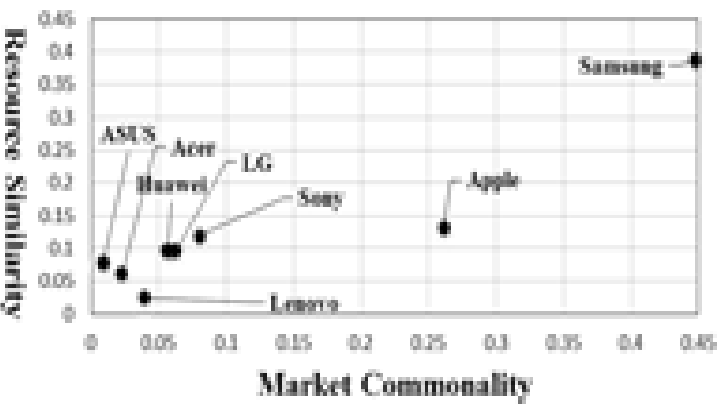

LG

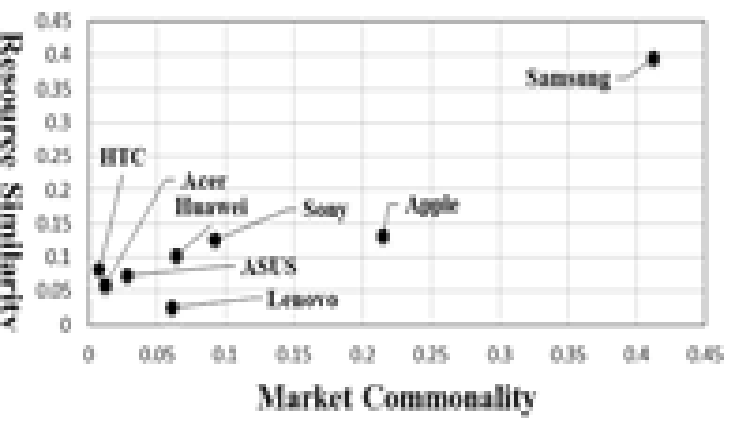

Huawei

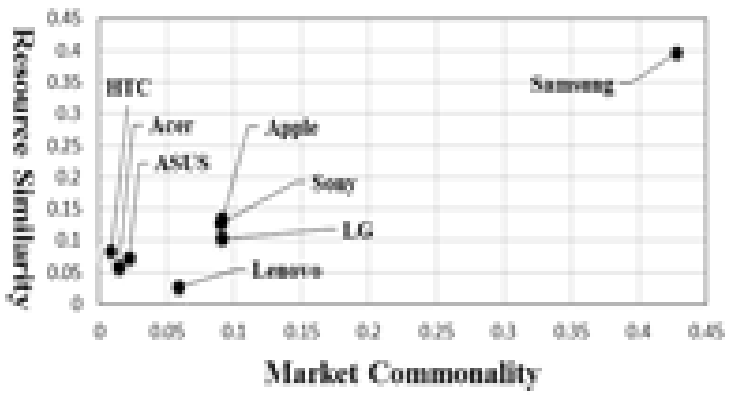

Lenovo

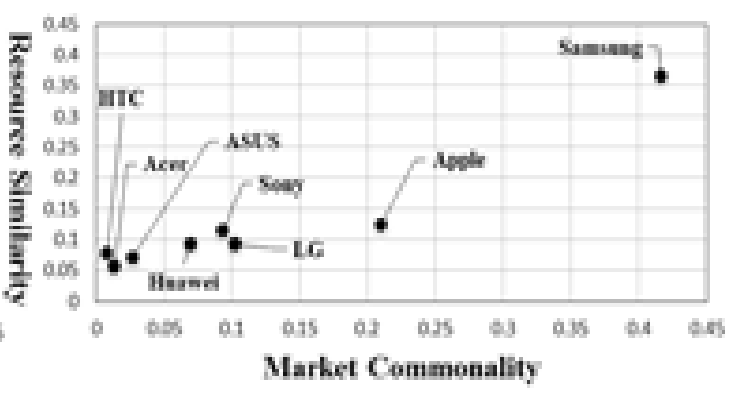

improves product quality and breakthroughs in specifications, but also becomes a world-famous smartphone brand manufacturer.

Huawei, as a late-entrants, in order to avoid direct competition with high-end brand manufacturers, using the devel- 
oping countries as the sales base. Not only avoids the multiple restrictions of entering the market threshold, but also penetrates the market with low-cost strategies. From the competitor mapping, we found that Huawei started to post a threat on Apple and Samsung and started to aggressively enter into the high-end smartphone market.
Apple

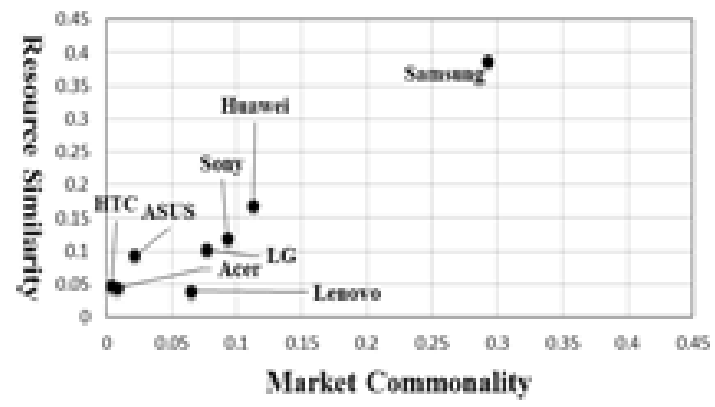

Samsung

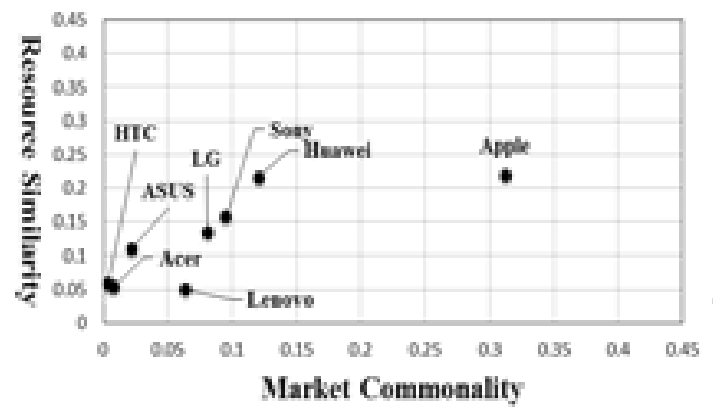

Sony

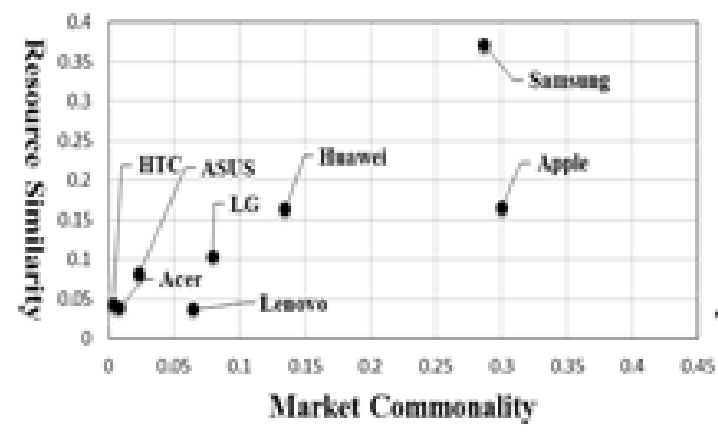

ASUS

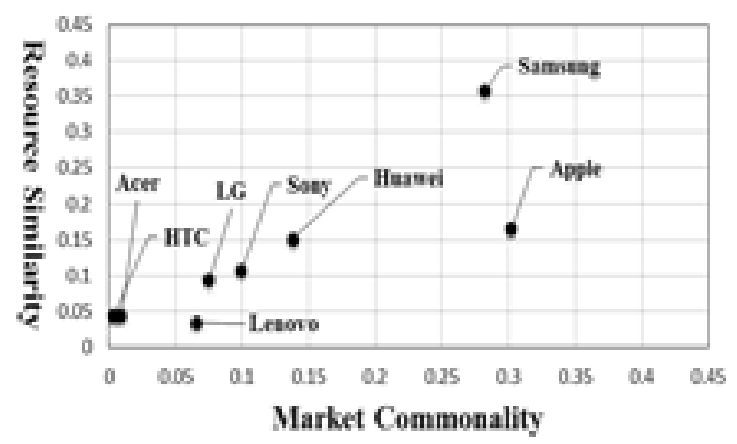

HTC

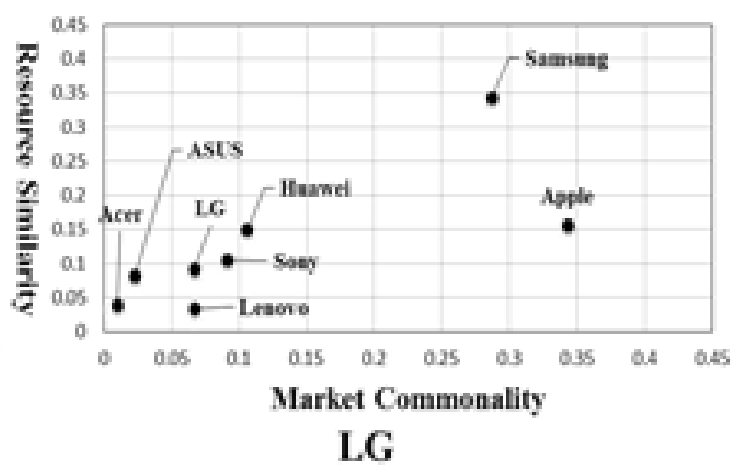

LG
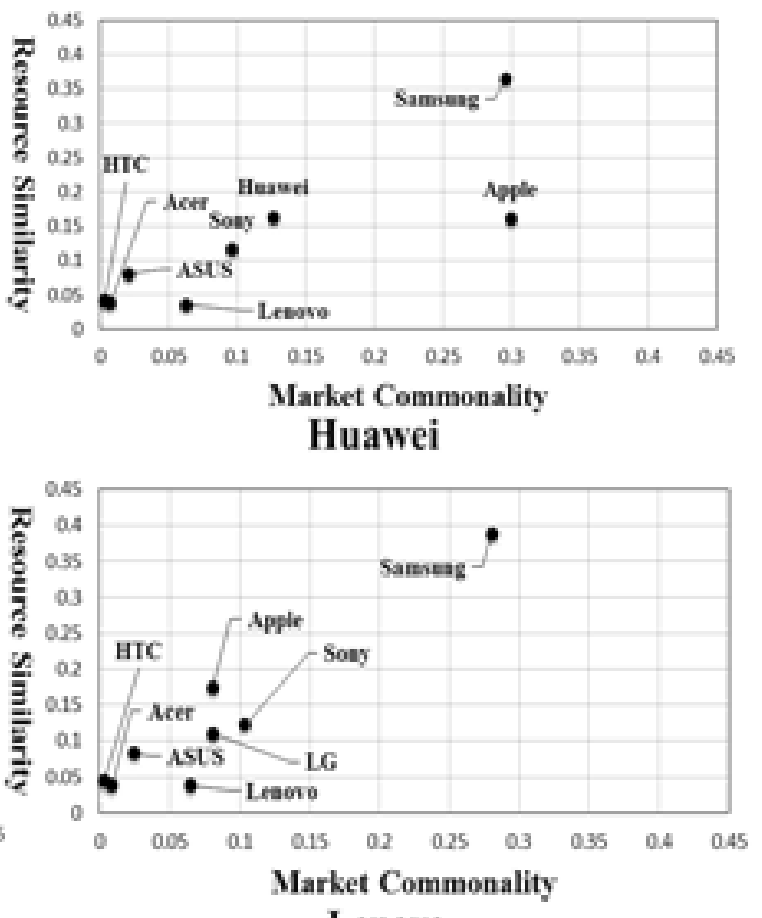

Lenovo

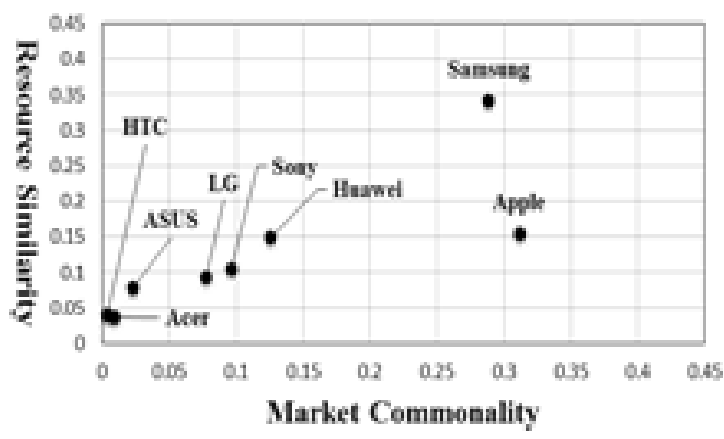

FIGURE 7. Competitor mapping in 2016 


\section{Driving Factors}

\section{Awareness}

According to IDC data, NOKIA accounted for more than $40 \%$ of the market share in the mobile phone market in 2007. At the time, the first smartphone launched by Apple in 2007 had a market share of only $3.3 \%$ at the end of the year. Even if NOKIA was aware of Apple's competitive actions, due to the huge market share gap, NOKIA had no motivation to respond to Apple's competitive actions.

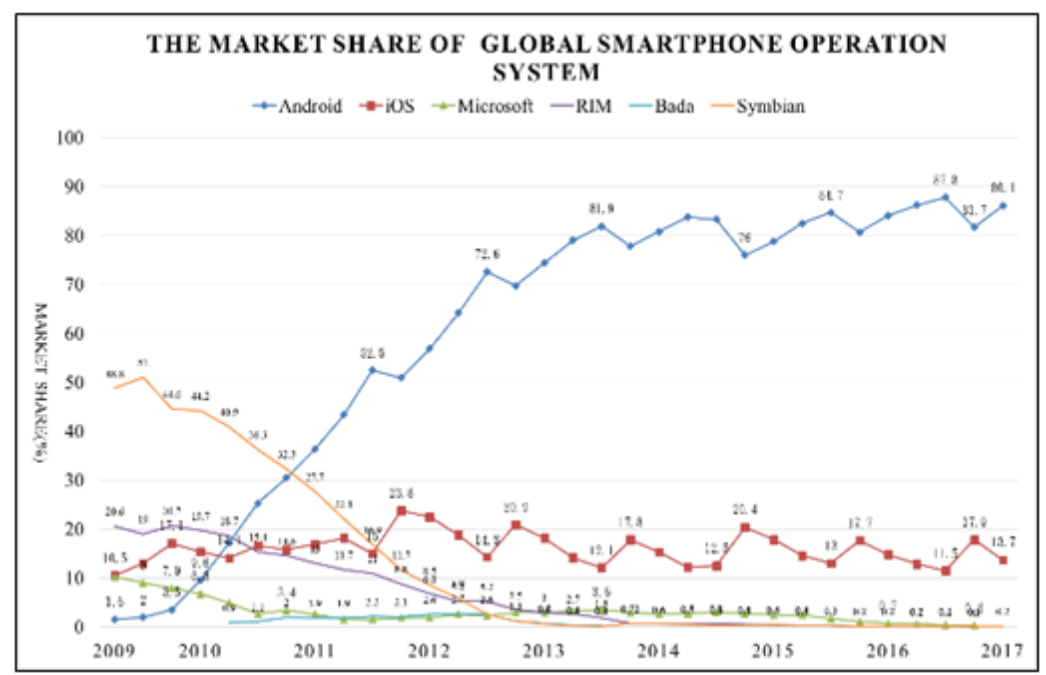

FIGURE 8. The market of global smartphone operation system

\section{Motivation}

In 2009, the shipment of the smartphone market continued to rise, leading to a significant decline in the feature phone market share. Because Apple's operating system IOS was developed for itself and not open to the public, leading to many competitors join the Open Handset Alliance (OHA) developed by Google. With the increasing number of competitors, the competition between operating systems becomes more intense. From the Figure 8, it can be found that in 2009 , the operating system was dominated by Sym- bian, IOS and Microsoft. But by 2010, the market share of Android operating systems was continuously rising. As a result, ISO, which had the largest operating system market share at that time, had the strong motivation to stop the continued growth of the Android operating system.

\section{Capability}

With early entry into the smartphone market, Apple has accumulated a lot of patents in the smartphone market by $\mathrm{M}$ and $\mathrm{A}$ and R\&D investment. Apple has strong motivation and sufficient ability to attack competitors on the market.

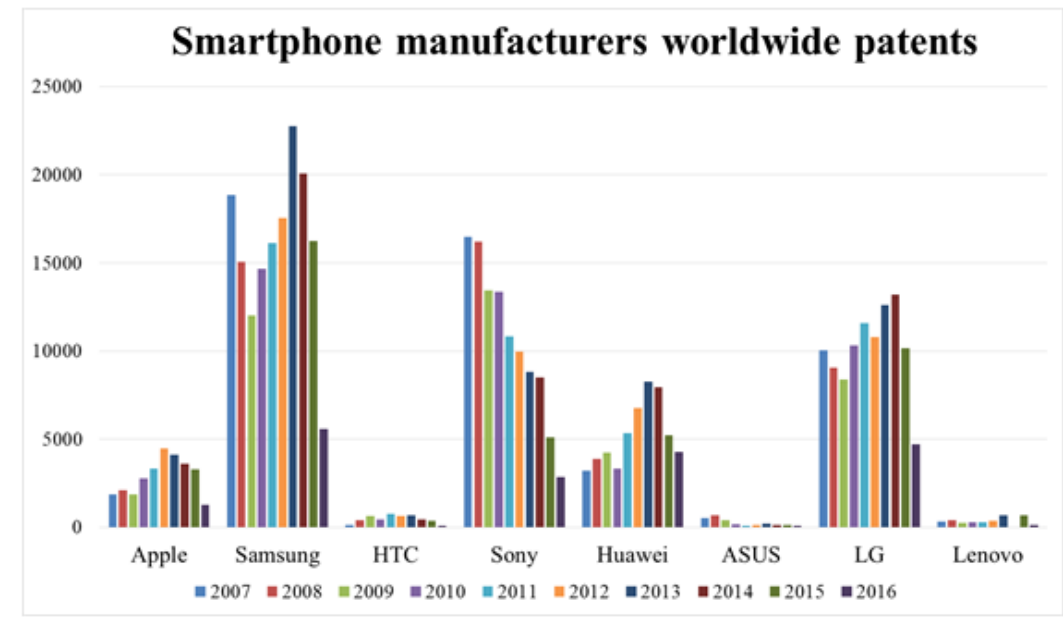

FIGURE 9. Smartphone manufacturers' worldwide patents 


\section{Competitive Action and Response}

Apple filed patent litigation with HTC in March 2010, from the United States, the United Kingdom to Germany; from smartphones to tablets; from patent infringement to prohibit sales orders until 2012, both parties signed a 10-year Patent licensing contract.

\section{Key factors of reconciliation}

Android operating system market share in 2012 has been close to $60 \%$, becoming the mainstream of operating system. The following are reasons why Apple is willing to settle with HTC:

a. For Apple, the smartphone that Samsung sells is a major source of growth for the Android operating system.

b. HTC also knows that Samsung is the true competitor of Apple. During the litigation period, the company chose to actively respond to lawyers and make full use of the administrative procedures to drag on and change strategies. It is reasonable and lawful to suspend most of the litigation cases so that Apple doesn't get the sweetness on HTC. Forcing Apple to focus on Samsung.

c. Much more late-entrants joined the market like Huawei, Lenovo, Xiaomi, and ZTE.

d. HTC acquires Standard Essential Patent (SEP) from the market, including from S3 Graphics, HP, ADC, Nokia, etc., which are also Apple's interest in interactivity section. From the Figure 7, HTC from 2007 to 2016, all the records of mergers and acquisitions are concentrated during the proceedings (2010-2011), in order to fight back to the Apple.

e. Apple will charge the patent license for Android-based vendors in the future to strive for the best value standard. For Apple, the real threat comes from Samsung, which sets the standard for patent grants with HTC to fight for a higher patent license. The standard will also be tackled by other Android smartphone manufacturers.

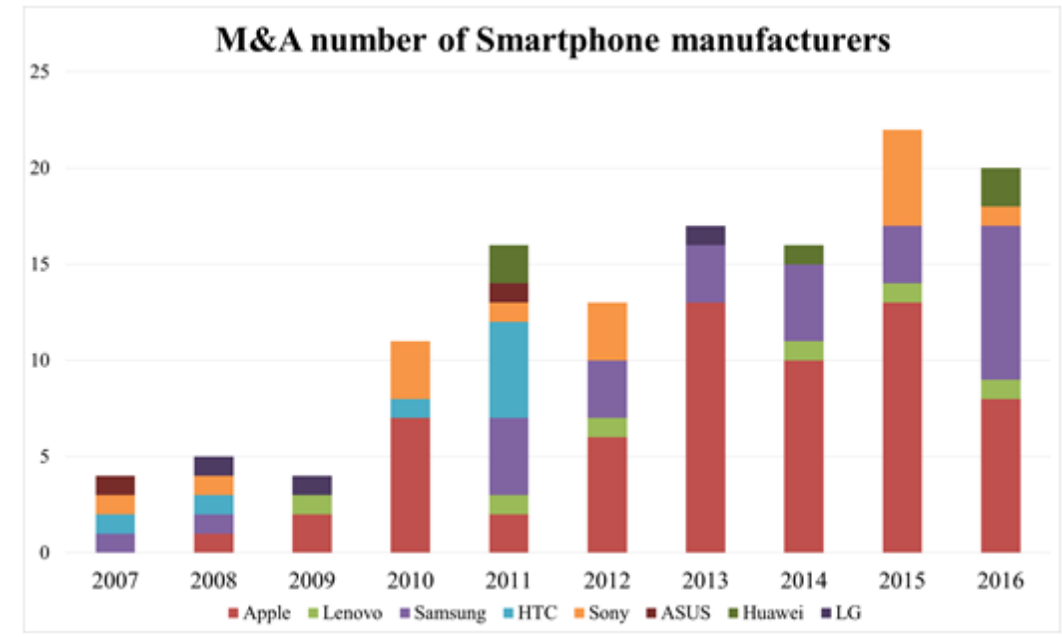

FIGURE 10. M\&A number of smartphone manufacturers

\section{Response between Apple and Samsung}

Apple's key components for many products are purchased from Samsung, and Apple is also Samsung's largest customer. When Apple first filed a patent suit against Samsung, Samsung quickly fight back in just six days. This represents that Samsung's market commonality and resource similarity both have a very high degree of overlap with Apple. Both regard each other as the most direct competitor, but dare not to take any action until one side breaks the deadlock. Once it breaks, then both sides will fight back as fast as possible. Samsung doesn't care about losing the big customer. Instead, Samsung chooses to fight back quickly, which means Samsung thinks it's more important to protect the brand image of her own company than to lose the big customers. Samsung can make up for the loss of orders from Apple by improving the brand image.

\section{Response between Samsung and Huawei}

From the Figure 8, the proportion of investment in $\mathrm{R}$ and $\mathrm{D}$ expenditures in total operational income of Huawei has been rising in recent years. Huawei realizes that only by continuously developing new technologies, improving product quality, and applying for patents can compete with competitors. Unanimously, Huawei chooses patent litigation as an aggressive attack. In May 2016, Huawei announced that it filed a patent infringement lawsuit against Samsung, alleging that Samsung's products violated Huawei's patents. The following is the purpose of Huawei suing Samsung. 
a. Snatch market share and increase revenue through patents, and declare to competitors that Huawei's achievements in patent research and development.

b. Forced a patent litigation with Samsung in order to reach an interactive licensing agreement with Samsung to obtain core technology and reduce the risk of attacking on the US smartphone market. c. Increase the operating costs of competitors. Reversing the image and status of passive in the past.

d. Enhancing brand image is a key factor for success in the international market. Choosing to sue Samsung for infringement can change the cheap impression of brands in China.

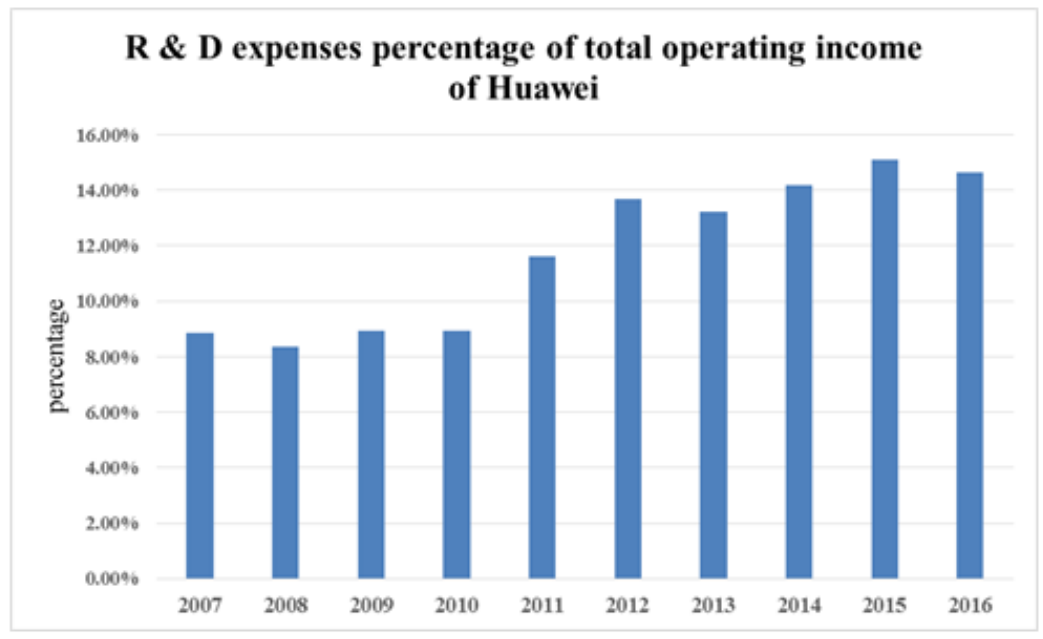

FIGURE 11. R\&D expenses percentage of total operating income of Huawei

\section{Efficiency Evaluation}

This study uses the Frontier Analyst application software for data envelopment analysis calculations. The following will further explain the causes behind each analysis result, and summarize the reasons and draw conclusions.

\section{Performance efficiency}

Apple suffered from the small size of the early smartphone market, resulting in efficiency that did not reach efficiency status. However, with the gradual expansion of the market, the overall efficiency has improved significantly.

HTC started from OEM, and has achieved good performance in the early stage under the multiple strategies of manufacturing OEM, ODM and OBM. Apple's excellent supply chain management capabilities make it difficult for products to be affected by the external environment regardless of the delivery and the price of key components. Samsung has excellent supply chain integration capabilities. When a large number of competitors enter the market, the launch time of product is not easily affected by the lack of capacity in the supply chain, and it can still be ahead of the competition. When HTC's product prices remain at the same high prices as Apple and Samsung, they are easily replaced. In recent years, with the appearance of low-end and mid-end smartphone manufacturers in China, HTC has missed the potential market. Under such circumstances, HTC's operating performance has declined significantly in recent years.

Samsung invests high $\mathrm{R}$ and $\mathrm{D}$ expenditures, marketing expenses, and vertical integration of high supply chains to improve product quality, rapidly introduce new products, in order to capture high-, mid-, and low-end smartphone markets. It is the same result with Liao and Lin (2011), the investment does not immediately reflect in operating income. The operating performance can only be maintained at approximately $70 \%$.

\section{Malmquist Index}

The Malmquist Index is an index that can measure changes in total factor productivity across periods. Due to the characteristics of the smartphone industry, each competitor enters the market with different time points, the challenges of market and the competitive environment are even more different. This study divides entry time of competitors into three phases, first-movers, early follower, and late-entrants to analyze and explain to understand what kind of competition strategy should be adopted in each competition period to survive in the competitive market. 
TABLE 1. Performance efficiency of smartphone manufacturers (Unit: Percentage)

\begin{tabular}{lllllllll}
\hline \hline & Apple & Asus & HTC & Huawei & LG & Lenovo & Samsung & Sony \\
\hline 2007 & 82 & 100 & 100 & 99 & 97 & 100 & 66 & 86 \\
2008 & 95 & 100 & 100 & 100 & 100 & 100 & 63 & 95 \\
2009 & 97 & 100 & 100 & 100 & 100 & 100 & 64 & 91 \\
2010 & 100 & 100 & 100 & 100 & 100 & 100 & 64 & 97 \\
2011 & 100 & 100 & 100 & 100 & 94 & 100 & 68 & 100 \\
2012 & 100 & 100 & 94 & 100 & 94 & 100 & 68 & 100 \\
2013 & 100 & 100 & 68 & 100 & 97 & 100 & 68 & 100 \\
2014 & 100 & 100 & 88 & 100 & 99 & 100 & 62 & 100 \\
2015 & 100 & 100 & 79 & 100 & 95 & 100 & 67 & 100 \\
\hline \hline
\end{tabular}

TABLE 2. Malmquist Index of smartphone manufacturers

\begin{tabular}{llllllllll}
\hline \hline & $\mathbf{2 0 0 7 -}$ & $\mathbf{2 0 0 8}-$ & $\mathbf{2 0 0 9 -}$ & $\mathbf{2 0 1 0}-$ & $\mathbf{2 0 1 1 -}$ & $\mathbf{2 0 1 2 -}$ & $\mathbf{2 0 1 3 -}$ & $\mathbf{2 0 1 4 -}$ & 2015- \\
& $\mathbf{2 0 0 8}$ & $\mathbf{2 0 0 9}$ & $\mathbf{2 0 1 0}$ & $\mathbf{2 0 1 1}$ & $\mathbf{2 0 1 2}$ & $\mathbf{2 0 1 3}$ & $\mathbf{2 0 1 4}$ & $\mathbf{2 0 1 5}$ & $\mathbf{2 0 1 6}$ \\
\hline Apple & 1.2642 & 1.1654 & 1.2546 & 1.2922 & 1.1825 & 0.7411 & 0.8820 & 1.0682 & 0.8023 \\
Samsung & 0.5859 & 1.5628 & 1.5630 & 0.7787 & 1.4816 & 1.1429 & 0.8326 & 1.1843 & 1.1174 \\
HTC & 0.7954 & 0.8504 & 1.0442 & 1.0475 & 0.8141 & 0.4960 & 1.1507 & 0.5771 & 0.7554 \\
Sony & 1.0384 & 0.8643 & 1.2940 & 1.0248 & 0.9573 & 1.0409 & 1.0637 & 1.1016 & 1.0140 \\
Huawei & 1.0000 & 0.9923 & 1.0729 & 0.8306 & 1.0495 & 1.0809 & 1.0882 & 0.9358 & 0.9413 \\
Asus & 0.7567 & 1.2310 & 1.2222 & 1.1102 & 1.1300 & 0.7071 & 1.0784 & 0.9940 & 1.0436 \\
LG & 1.0360 & 1.0953 & 0.7513 & 0.9644 & 1.0815 & 0.9165 & 1.0276 & 0.9035 & 1.0386 \\
Lenovo & 1.1784 & 0.7493 & 1.0498 & 0.9392 & 0.9757 & 0.8588 & 1.0575 & 0.8049 & 0.8345 \\
\hline \hline
\end{tabular}

\section{First-movers - Apple, HTC}

The advantage of pioneers is that there are not many competitors in the market, and they have absolute advantages in product pricing and market share. With the excellent supply chain management capabilities, and continuing to acquire the latest technology from the market every year, Apple integrates the latest technology into its own products, enabling the company to maintain innovative breakthrough capabilities. From the Table 2, by 2013, with the emergence of dominant design, many competitors chose to enter the market at this stage, and almost all the manufacturers were affected, resulting in the decline of the Malmquist Index. The HTC lost the market for mid- and low-end market because of the late-entrants' accession. In 2013, compared to 2012, the Malmquist Index had a serious decline to 0.496 .

\section{Early follower - Samsung, LG, Sony}

Early followers are all manufacturers of feature phone. No matter whether they are in the market or on the sales channel, they are better than the First-movers. However, due to the uncertainty of the early smartphone market, they are not willing to invest. Until the market is shaped, competition will be based on the past experience and the resources accumulated in the market. According to an international research and consulting firm, Gartner, announced the list of top ten supply chain leaders in the Asia Pacific region in 2014. Five companies, including early followers and latecomers, are in the top ten of the supply chain leaders. Excellent supply chain leaders have common key capabilities, including building a consumer-centric supply chain, serving local and global customers, enhancing risk management processes, improving cross-functional communication, and driving operational performance. Based on the above key capabilities, the Malmquist Index still has a good performance.

\section{Late-entrants-ASUS, Lenovo}

For the late-entrants, how to increase the shipment and market share of the products after entering the market and avoid the attacks of competitors in the market is the key to survive in the fierce market. Huawei, Lenovo, and ASUS all prefer to use developing countries as their sales base. Benefiting from the huge population of developing countries, they can reduce manufacturing unit costs through mass production. At this point, dominant design has emerged. The late-entrants only need to research on specifications, and no longer need to invest too much in product development, narrowing the gap with competitors. In order to enter the high-end smartphone market, Huawei continuously invests high $\mathrm{R}$ and $\mathrm{D}$ expenses every year to improve product 
specifications and quality. Because only the high-end smartphone market can gain greater profits.

\section{BCG matrix}

In this section, BCG matrix is combined the horizontal and vertical axis of the matrix with the results of DEA analysis which are performance efficiency and Malmquist Index respectively.

The center point of the vertical axis is 1, which means that when the company's average Malmquist Index (AMI) is greater than 1 , on average, the company grows every year. The horizontal axis has a central value of 0.5 and the maximum value is 1 . When the average performance efficiency of company (APE) is less than 0.5, it represents that the operating efficiency of company is lower than all of the peers. The four types are defined as follows:

When $A M I \geq 1$ and APE $\geq 0.5$, both the Macquarie Index and the performance efficiency are quite outstanding, so this type of company is classified as the Stars.

When AMI $<1$ and APE $\geq 0.5$, although the efficiency of performance is better than peers, the Malmquist Index has a tendency of recession, which means that the competitiveness of enterprises is declining year by year, but it still can bring considerable revenue to the company. Therefore, this type of company is classified as Cash Cows.

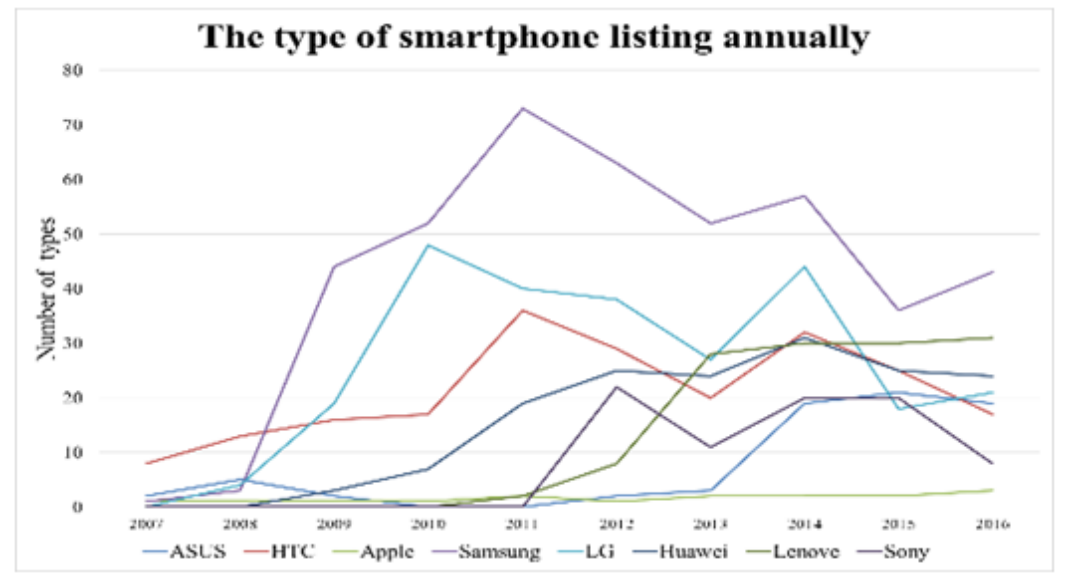

FIGURE 12. The type of smartphone listing annually

When AMI $\geq 1$ and APE $<0.5$, The Malmquist Index of company has grown year by year, representing that companies maintain at a high level of competitiveness, but is affected by the poor internal operating performance, so this type of company is classified as a Problem Childs.

When AMI $<1$ and APE $<0.5$, Neither the Malmquist Index nor the performance efficiency can compete with its peers. If continuous investment will affect the overall operating performance of the company, this type of company is classified as Dogs. All companies fall between the stars and cash cows. In general, all the efficiency performance of companies above the standard. When an enterprise wants to enter the area of stars, the Malmquist index must be above 1. It also means that operational efficiency is the basic ability of the company to compete, and the ability to stand with continuous growth.

TABLE 3. Combining DEA with BCG matrix

\begin{tabular}{llllll}
\hline \hline & 2007-2008 & 2008-2009 & 2009-2010 & 2010-2011 & 2011-2012 \\
\hline Apple & Stars & Stars & Stars & Stars & Stars \\
Asus & Cash Cows & Stars & Stars & Stars & Stars \\
HTC & Cash Cows & Cash Cows & Stars & Stars & Cash Cows \\
Huawei & Cash Cows & Cash Cows & Stars & Cash Cows & Stars \\
LG & Stars & Stars & Cash Cows & Cash Cows & Stars \\
Lenovo & Stars & Cash Cows & Stars & Cash Cows & Cash Cows \\
Samsung & Cash Cows & Stars & Stars & Cash Cows & Stars \\
Sony & Stars & Cash Cows & Stars & Stars & Cash Cows \\
\hline \hline
\end{tabular}


Table 3. Continue....

\begin{tabular}{lllll}
\hline \hline & 2012-2013 & 2013-2014 & 2014-2015 & 2015-2016 \\
\hline Apple & Cash Cows & Cash Cows & Stars & Cash Cows \\
Asus & Cash Cows & Stars & Cash Cows & Stars \\
HTC & Cash Cows & Stars & Cash Cows & Cash Cows \\
Huawei & Stars & Stars & Cash Cows & Cash Cows \\
LG & Cash Cows & Stars & Cash Cows & Stars \\
Lenovo & Cash Cows & Stars & Cash Cows & Cash Cows \\
Samsung & Stars & Cash Cows & Stars & Stars \\
Sony & Stars & Stars & Stars & Stars \\
\hline \hline
\end{tabular}

\section{CONCLUSION}

In recent years, Taiwan's economy has grown slowly, and enterprise must find new growth drivers. Continuous investment in R\&D and innovation, or access to new technologies through mergers and acquisitions, is a way to help companies grow. The following are the results of this study to provide direction for the progress and improvement of Taiwan manufacturers.

1. The Samsung Group was affected by a huge business and the overall operating performance was maintained at approximately $70 \%$, demonstrating that large-scale may not be better. The capital of Taiwanese companies may not be able to compete with international companies. Maintaining good operating performance has become a fundamentally important key factor.
2. Before the emergence of dominant design, most of the competitive strategy were patent applications, patent litigation, and intellectual property rights. After dominant design emerged, companies began to use the supply chain integration, sales channels, and brand value as the main competition methods. Taiwan manufacturers have been affected in the early days by ignoring the importance of patent. Subsequent efforts should focus on supply chain integration, sales channels, and brand value.

3. According to the analysis results of this study, the Malmquist Index is a key factor to measure whether the company has continued to growth. Apple and Samsung have chosen to quickly acquire key technologies through M\&A. While Huawei continues to increase its annual investment in $\mathrm{R}$ and $\mathrm{D}$, these decisions will affect the Malmquist index.

\section{REFERENCES}

Al-Sharkas, A. A., Hassan, M. K., \& Lawrence, S. (2008). The impact of mergers and acquisitions on the efficiency of the US banking industry: Further evidence. Journal of Business Finance \& Accounting, 35(1-2), 50-70. doi:https://doi.org/ 10.1111/j.1468-5957.2007.02059.x

Avkiran, N. K. (2006). Developing foreign bank efficiency models for dea grounded in finance theory. Socio-Economic Planning Sciences, 40(4), 275-296. doi:https://doi.org/10.1016/j.seps.2004.10.006

Barney, J. (1991). Firm resources and sustained competitive advantage. Journal of Management, 17(1), 99-120. doi:https:// doi.org/10.1177/014920639101700108

Charnes, A., Cooper, W. W., \& Rhodes, E. (1978). Measuring the efficiency of decision making units. European Journal of Operational Research, 2(6), 429-444. doi:https://doi.org/10.1016/0377-2217(78)90138-8

Chen, M. J. (1996). Competitor analysis and interfirm rivalry: Toward a theoretical integration. Academy of Management Review, 21(1), 100-134. doi:https://doi.org/10.5465/amr.1996.9602161567

Chen, M. J., \& MacMillan, I. C. (1992). Nonresponse and delayed response to competitive moves: The roles of competitor dependence and action irreversibility. Academy of ManagementJournal, 35(3), 539-570. doi:https://doi.org/10.2307/ 256486

Chen, Y. S., \& Chen, Y., B. (2009). Using Data Envelopment Analysis (DEA) to evaluate the operational performance of the wafer fabrication industry in Taiwan. Journal of Manufacturing Technology Management, 20(4), 475-488. doi:https:// doi.org/10.1108/17410380910953739

Conner, K. R. (1994). The resource-based challenge to the industry-structure perspective. In Proceedings of Academy Management. Briarcliff Manor, NY.

Cook, W. D., \& Seiford, L. M. (2009). Data Envelopment Analysis (DEA) thirty years on. European Journal of Operational Research, 192(1), 1-17. doi:https://doi.org/10.1016/j.ejor.2008.01.032 
Cooper, W. W., Seiford, L. M., \& Tone, K. (2006). Data variations. Introduction to Data Envelopment Analysis and Its Uses: With DEA-Solver Software and References, 3(5), 271-300.

Emrouznejad, A., \& Yang, G.-l. (2018). A survey and analysis of the first 40 years of scholarly literature in DEA: 1978-2016. Socio-Economic Planning Sciences, 61, 4-8. doi:https://doi.org/10.1016/j.seps.2017.01.008

Endang, K. (2017). The effect of investment decision financing decision dividend payment policy and company size. Journal of Administrative and Business Studies, 3(2), 105-113. doi:https://doi.org/10.20474/jabs-3.2.5

Harrigan, K. R. (1985). An application of clustering for strategic group analysis. Strategic Management Journal, 6(1), 55-73. doi:https://doi.org/10.1002/smj.4250060105

Lee, S., Lee, K., \& Kang, I. W. (2005). Efficiency analysis of controls in EDI applications. Information \& Management, 42(3), 425-439. doi:https://doi.org/10.1016/j.im.2001.09.001

Liao, C.-H., \& Lin, H.-Y. (2011). Measuring operational efficiency of mobile operators in Japan and Korea. Japan and the World Economy, 23(1), 48-57. doi:https://doi.org/10.1016/j.japwor.2010.11.001

Montgomery, C. A. (1985). Product-market diversification and market power. Academy of Management Journal, 28(4), 789-798. doi:https://doi.org/10.2307/256237

Smith, K. G., \& Grimm, C. M. (1991). A communication-information model of competitive response timing. Journal of Management, 17(1), 5-23. doi:https://doi.org/10.1177/014920639101700102

Srisangkaew, K. (2017). Advanced destination marketing strategy for Chanthaburi Province, thailand. International Journal of Business and Economic Affairs, 2(1), 77-84. doi:https://doi.org/10.24088/ijbea-2017-21010

Sundar, C. S., \& Al Harthi, F. N. S. (2015). Impact of capital structure on firm's profitability with reference to companies listed on MSM (Muscat Securities Market). International Journal of Business and Administrative Studies, 1(1), 23-28. doi:https://doi.org/10.20469/ijbas.10004

Thanassoulis, E. (2000). Dea and its use in the regulation of water companies. European Journal of Operational Research, 127(1), 1-13. doi:https://doi.org/10.1016/s0377-2217(99)00436-1 